\title{
Effect of Weather on Diamond Back Moth, Plutella xylostella (L.) (Lepidoptera: plutilidae) in District Haripur
}

\author{
Bashir Ahmad $^{1 *}$, Ahmad-Ur-Rahman Saljoqi', Hayad Zada ${ }^{2}$, Shahid Sattar ${ }^{1}$, Toheed Iqbal ${ }^{3}$, Saddam \\ Hussain $^{1}$ and Muhammad Saeed ${ }^{4}$
}

${ }^{1}$ Department of Plant Protection, The University of Agriculture, Peshawar, Khyber Pakbtunkhwa, Pakistan.; ${ }^{2}$ Senior Instructor Agriculture Training Institute Peshawar, Khyber Pakbtunkhwa, Pakistan; ${ }^{3}$ Department of Entomology, The University of Agriculture Peshawar, Khyber Pakbtunkbwa, Pakistan; ${ }^{4}$ Department of Entomology, The University of Haripur, Khyber Pakbtunkbwa, Pakistan.

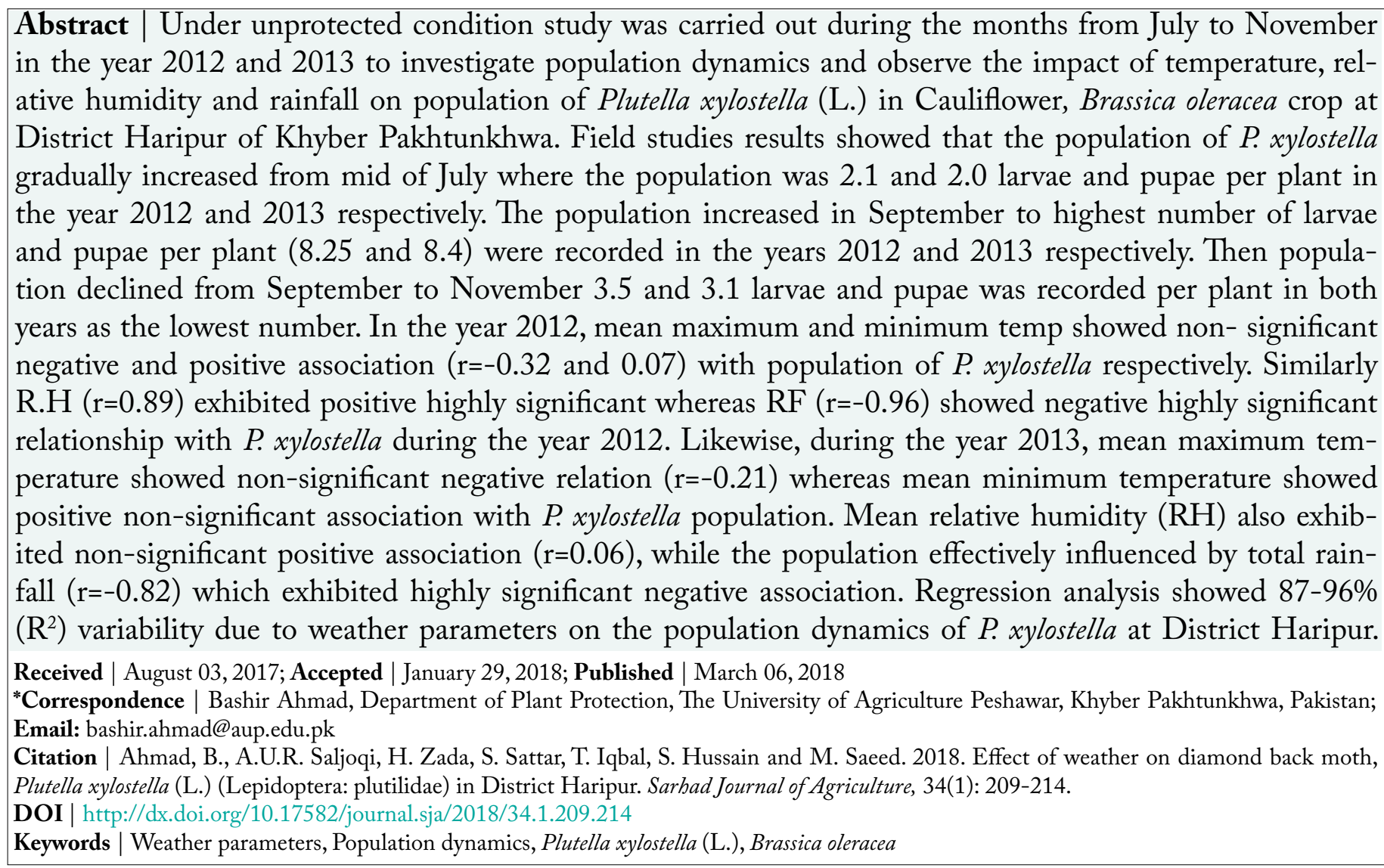

\section{Introduction}

$\mathrm{C}$ auliflower, Brassica oleracea, belongs to family cruciferace which is a very diverse group comprises 350 genera and more than 3,500 cultivated and wild plants species (Warwick et al., 2003). Cau- liflower is basically a cool season vegetable having a temperature requirement for growth and heading is between $15^{\circ} \mathrm{C}$ and $20^{\circ} \mathrm{C}$. Pakistan is among the top ten producing countries of this vegetable in the world (FAO, 2008). The production of Cauliflower has been reduced by several factors including insect pests such 
as Diamond back moth (DBM), Plutella xylostella, Aphids (Brevicoryne brassicae, (Innaeus) Lipaphis erysimi (Kaltenbach), Myzus persicae (Sulzur), Cabbage worms and flea beetles (Phyllotreta spp.), butterfly (Pieris spp.) and diseases such as black rot and club root (Nyambo and Pekke, 1995).

Diamond back moth (DBM) is a highly destructive insect pest of $B$. oleracea throughout the world (You and Wei, 2007) and is the most widely distributed insect pest of all Lepidopterous insects (Shelton, 2004). P. xylostella is an oligophagous pest as the larvae feed on a number of crucifer ace crops including cabbage, cauliflower, broccoli, radish, turnip and mustard (Thorsteinson, 1953). The DBM is available throughout the year provided that due availibility of food source for the DBM larvae (Leu and Lee, 1984) causing damage to the cruciferous plants (Chin et al., 1990). P. xylostella has about 21 generation per year ((Leu and Lee, 1984) but in temperate and tropical regions it has 4 to 20 generations (Vickers et al., 2004).

In Pakistan, DBM is a key pest of cauliflower (Mushtaque et al., 1995) and in most situation, cause, s about 100\% loss (Abro et al., 1994) whereas Verkerk and Wright (1996) reported 90\% losses of yield in Pakistan. The economic threshold level of DBM is about of $0.05 /$ plant (Hartcoutr et al., 1957). However, no research has been conducted on population dynamics and forecasting of its outbreak. For strategic planning and tactical decision making the knowledge of pest species level of abundance, pest pressure, timing is highly important (Maelzer et al. 1996). In general pest population forecasting become a difficult task as many factors influence it (Muthuthantri et al. 2010) such as a biotic and biotic factors e.g. temperature, rainfall and relative humidity and natural enemies for a key pest all years round available, it is important to develop long term population forecasts would be particularly effective (Zalucki et al. 2009).

Keeping in view this factor an up to date knowledge of the occurrence pattern of diamondback moth cauliflower. Crop in relation with weather parameter is a prerequisite for implementation of an effective and successful management tactics against this pest. The present research was consequently conducted to observe and monitor the population dynamics of $P$. xylostella on cauliflower and determine the effects of maximum and minimum temperature, percent relative humidity and rainfall on population trend.

\section{Materials and Methods}

To study the population dynamics of Plutella xylostella (L.) in cauliflower, the experimental procedures of Mohamed (2004) and Kfir (1998) with some modification was used. The population dynamics of $P$. xylostella was examined in District Haripur, Khyber Pakhtunkhwa in the cropping seasons from July to November during the years 2012 and 2013 and were correlated with abiotic climatic factors including mean maximum and minimum temperature, relative humidity and rainfall.

Standard agronomic practices were used in the field of cauliflowers that were included normal weeding, irrigation practices, fertilization and sanitation etc. Experiments were laid down in a randomized complete block design (RCBD) having experimental unit size of $5 \mathrm{~m}$ in width and $5 \mathrm{~m}$ in length within the experimental field. Each experimental unit was consisting of Forty (40) cauliflower plants, having five (5) rows and every row was having eight (8) plants. For studying population dynamics of $P$. xylostella, each experimental unit was replicated four times within the experimental field.

Five infested plants were randomly selected from each replication and were thoroughly inspected fortnightly and the numbers of P. xylostella larvae and pupae were counted but not removed. The experiment was continued until harvest in both years. Population of $P$. $x y$ lostella was determined as the mean numbers of larvae and pupae per cauliflower plant. Observations were recorded for each plant and the mean maximum and minimum temperature, relative humidity and rainfall were noted. Data regarding maximum and minimum temperature, relative humidity and rainfall were taken from Meteorological Department and were correlated with the population dynamics of Diamond Back Moth, P. xylostella.

\section{Statistical analysis}

The data was subjected to correlation (Pearson) analysis and linear multiple regression by using Statistical Software Statistix 8.1 (Bowden and Morris, 1995).

\section{Results and Discussion}

\section{Population dynamics of diamondback moth}

Population of Plutella xylostella (L.) was gradually started building up after transplanted the cauliflower, 
Table 1: Population dynamics of P. xylostella (L.) taken Fortnightly with mean weather parameters on Cauliflower at District Haripur, during the year 2012 and 2013.

\begin{tabular}{|c|c|c|c|c|c|c|c|c|c|c|c|}
\hline & 2012 & & & & & 2013 & & & & & \\
\hline Date & Pop & T.Max & T.Min & $\mathrm{RH}$ & $\mathrm{RF}$ & Date & Pop & T. Max & T.Min & R.H & R.F \\
\hline July 15 & 2.1 & 33.5 & 19.9 & 68 & 1320 & July 15 & 2 & 31.3 & 19 & 72 & 1145 \\
\hline July 30 & 2.85 & 33.1 & 19.7 & 70 & 1060 & July 30 & 2.15 & 30.3 & 19.5 & 92 & 987 \\
\hline Aug,14 & 4.85 & 31.6 & 19 & 80 & 870 & Aug, 14 & 4.95 & 29.5 & 19 & 95 & 754 \\
\hline Aug, 29 & 6.65 & 27.2 & 18 & 87 & 449 & Aug,29 & 6.5 & 27.7 & 18.8 & 85 & 653 \\
\hline Sep, 13 & 7.7 & 27.6 & 17.1 & 90 & 399 & Sep, 13 & 6.55 & 27.1 & 16.7 & 81 & 289 \\
\hline Sep, 28 & 8.25 & 27.2 & 16.5 & 82 & 324 & Sep, 28 & 8.4 & 26.5 & 16.1 & 79 & 329 \\
\hline Oct, 13 & 5.3 & 26 & 8 & 80 & 549 & Oct, 13 & 5.05 & 25.8 & 9.5 & 80 & 465 \\
\hline Oct, 28 & 4.65 & 23 & 7.2 & 73 & 862 & Oct, 28 & 4.85 & 23.2 & 7.9 & 72 & 567 \\
\hline Nov, 12 & 3.5 & 22.2 & 4 & 73 & 987 & Nov, 12 & 3.1 & 21.5 & 5 & 69 & 578 \\
\hline
\end{tabular}

Brassica oleracea seedlings in the experimental field and at the mid of July, population was 2.1 and 2.0 larvae and pupae per plant in the year of 2012 and 2013 respectively as depicted in Table 1 . The highest numbers of larvae and pupae (8.25 and 8.4) per recorded at the end of September (Table 1) in both years of the research. From both years of the experiment it is highly obvious that peak population of $P$. xylostella persist from mid of August to mid of October as shown in the Table 1. A trend of decline in the cropping seasons from July to November was observed after the end of October in both years of the experiment and the lowest population of $P$. xylostella on cauliflower crops was recorded in the mid of November as 3.5 and 3.1 (Table 1) larvae and pupae per plant in the year 2012 and 2013 respectively.

Studying the population trends of $P$. xylostella on $B$. oleracea at district Haripur of Khyber Pakhtunkhwa from July to November in the year 2012 showed peak populations from August to October (6.65, 7.7, 8.25 and 5.3) as the highest number of larvae and pupae per plant were recorded in these months (Table 1). Likewise, during the year 2013 similar trend of $P$. xylostella population were observed as 6.5, 6.55, 8.4 and 5.05 (Table 1) larvae and pupae per plant were counted on August, 29, September 13, 28 and October 13. Ahmad and Ansari (2010) reported that the population of the DBM showed increased in the month of August and September and then gradually declined. These results are in agreement with the finding of Ahmad and Ansari (2010). Climatic conditions, including higher temperatures and decreased rainfall were cited as major factors which regulate the population dynamics of P. xylostella (Harcourt, 1986) while hot and dry conditions are known to be conducive for P. xylostella (Shelton, 2001). Similarly according to Patra et al. (2013) high temperatures favored the multiplication and development of $P$. xylostella while cold temperatures in November-February limited its population dynamics. As incidence of pest depends on host availability and climatic condition, therefore, incidence and peak infestation of pest vary from region to region. Results are similar with the study of Venkateswarlu et al. (2011) who reported that peak incidence of diamond back moth was observed during 1 st week of September.

\section{Correlation matrix of P. xylostella population dynam- ics with mean maximum and minimum temperature, \% relative bumidity $(R H)$ and rainfall $(R F)$ in 2012 and 2013}

During the year 2012, mean maximum and minimum temperatures have non- significant negative and positive association ( $r=-0.32$ and 0.07$)$ as shown in table II, with the population of diamondback moth, $P . x y$ lostella respectively. Similarly R.H ( $\mathrm{r}=0.89)$ exhibited positive highly significant relation with the population dynamics of $P$. xylostella whereas RF $(\mathrm{r}=-0.96)$ showed negative highly significant relationship with DBM population in District Haripur during the year 2012 (Table 2). Likewise, table II clearly explained that in the year 2013 of the research, the population of $P$. xylostella has influenced by the weather parameters. Mean Maximum temperature showed non-significant negative relationship $(r=-0.21)$ whereas the mean minimum temperature has positive non-significant correlation $(\mathrm{r}=0.06)$ with the population of $P$. xylostella.

Population dynamics of $P$. xylostella has showed non-significant positive association $(\mathrm{r}=0.11)$ with inks archers 
mean percent relative humidity but has greatly influenced by total rainfall ( $\mathrm{r}=-0.81)$ which exhibited highly significant negative association (Table 2). Present findings of our research are in close conformity with the observation of Venkateswarlu et al. (2011) who reported that among different climatic factors, maximum and minimum temperature had significant positive correlation whereas percent relative humidity showed significant negative correlation with $P$. xylostella population. Hemchandra and Singh (2007) reported that higher temperature, lower relative humidity and lower total rainfall, seem to favour the pest population build up. According to Loher et al. (2007) the growth and development of $P$. xylostella are significantly influenced by the prevailing weather variables, especially temperature and rainfall in the field. Ahmad et al. (2015) further investigated that temperature has positive correlation with population dynamics of $P$. xylostella, whilst rainfall negatively affect the population build up the said pest.

Table 2: Correlation Matrix of P. xylostella in District Haripur in the year 2012 and 013.

$\begin{array}{lll}\text { Weather Parameters } & \begin{array}{l}\text { Correlation coefficient for P. xy- } \\ \text { lostella population at Distt. Haripur }\end{array} \\ & 2012 & 2013 \\ \text { Mean Max temp }\left(\mathrm{C}^{0}\right) & -0.32 & -0.21^{\mathrm{NS}} \\ \text { Mean Min Temp }\left(\mathrm{C}^{0}\right) & 0.07 & 0.06 \\ \text { Mean R.H (\%) } & 0.89^{* *} & 0.11 \\ \text { Total Rainfall (mm) } & -0.96^{* *} & -0.81^{* *} \\ \text { NS: Non Significant; *: Significant O.05 level of probability; **: } \\ \text { Higbly Significant at O.01 level of probability; T Max: Maximum } \\ \text { Temperature C; T Min: Minimum Temperature C'; R.H: Mean } \\ \text { Percent Relative Humidity; R.F: Rain fall (mm). }\end{array}$

Table 3: Multiple regression equation for $P$. xylostella in District Haripur during the years 2012 and 2013.

$\begin{array}{lll}\text { Year } & \text { Multiple Regression equation } & \mathbf{R}^{2} \text { Value } \\ 2012 & \mathrm{Y} 1=12.95-0.22 \mathrm{X} 1+0.16 \mathrm{X} 2-0.002 \mathrm{X} 3- & 96.36 \% \\ & 0.005 \mathrm{X} 4 & \\ 2013 & \mathrm{Y} 2=13.82-0.28 \mathrm{X} 1+0.34 \mathrm{X} 2-0.02 \mathrm{X} 3- & 87.56 \% \\ & 0.006 \mathrm{X} 4 & \end{array}$

Y1 and Y2: Population of DBM; X1: Temperature maximum; X2: Temperature minimum; X3: Percent relative humidity.

Regression equations (Table 3) of P. xylostella indicates that during the year $2012,96.36 \%\left(\mathrm{R}^{2}\right)$ of variation in the population has influenced by weather parameters, while in the year $2013,87.56 \%\left(\mathrm{R}^{2}\right)$ of the deviation in the population has caused by the weather parameters. So the total variation in the population March 2018 | Volume 34 | Issue 1 | Page 212 of the $P$. xylostella due to weather parameters in both years of studies was $87-96 \%\left(\mathrm{R}^{2}\right)$. These results are in close concordance with the finding of Ahmad et al. (2015) who reported that weather parameters can influenced the population dynamic of $P$. xylostella up to $90-98 \%\left(\mathrm{R}^{2}\right)$. Nonetheless, Zada et al. (2014) also reported that Cydia pomonella population has greatly influenced by weather parameters Swat Pakistan, which ranges from $68-82 \%\left(\mathrm{R}^{2}\right)$. This equation can be used for predicting the population dynamics and establishment of an effective Integrated Pest Management Programme (IPM) for Plutella xylostella on cauliflower.

\section{Conclusions and Recommendation}

1. The results of the field study revealed that the incidence of Diamondback moth (DBM), steadily increase from mid of July where the population was 2.1 and 2 larvae and pupae per plant during both the years of studies.

2. The peak population of P. xylostella was recorded at the end of September (8.25 and 8.4 larvae and pupae /plant) in 2012 and 2013 respectively.

3. After September in both years of the research, declined in the population has been observed and the lowest population of 3.5 and 3.1 larvae and pupae/plant were counted in the mid of November.

4. Population dynamics of P. xylostella has showed great affinity with the temperature, relative humidity and rainfall and therefore, influenced by the weather parameters. Mean Maximum temperature showed non-significant negative relation $(\mathrm{r}=-0.24)$ whereas mean minimum temperature has exhibited positive non-significant association with the $P$. xylostella population. Mean percent relative humidity proved non-significant positive association $(\mathrm{r}=0.06)$ while total rainfall $(\mathrm{r}=-0.81)$ has greatly influenced the pest population by establishing a highly significant negative association.

5. Multiple regression analysis indicated 87-96\% (R2) variability due to meteorological parameters in the population dynamics of $P$. xylostella at District Haripur.

6. This model can be used for estimating and forecasting the population dynamics index of diamondback moth for its effective management. Besides, this model will also be helpful to find out proper time for spray application and implemen- 
tation of other management techniques to eliminate economic injury to the cauliflower.

\section{Acknowledgement}

The author is highly acknowledged Department of Agriculture, University of Haripur, Metrological Department of Khyber Pakhtunkhwa, for their help in getting Meteorological data and other relevant information.

\section{Author's Contribution}

Bashir Ahmad is the main researcher. Ahmad ur Rahman Saljoki supervised the research work while Muhammad Saeed co-supervised the research. Shahid Sattar did statistical designing. Toheed Iqbal helped in field work preparation and data analysis. Hayat Zada contribute in data entry research layout. Saddam Husain helped in writing the manuscript.

\section{References}

Abro, G.H., A.L. Jayo and T.S. Syed. 1994. Ecology of Diamondback moth, Plutella xylostella (L.) (L) in Pakistan. Host Plant Preference. Pak. J. Zool. 26(1):35-38.

Ahmad, B., A.U.R. Saljoqi, M. Saeed, F. Ullah and I. A. Khan. 2015. Population dynamics of Plutella xylostella (L.) in cauliflower and its correlation with weather parameters at Peshawar, $\mathrm{Pa}$ kistan. J. Entomol. Zool. Stud. 3 (1): 144-148.

Ahmad, T. and M.S. Ansari. 2010. Studies on seasonal abundance of diamondback moth Plutella xylostella (Lepidoptera: Plutellidae) on cauliflower crop. J. Plant Prot. Res. 50(3): 280-287. https://doi.org/10.2478/v10045-010-0049-6

Bowedn,J. and M.G.Morris. 1995. The influence of moon light on catches of insects in light traps in Africa. Part III. The effective radius of nursery vapour light trap and the analysis of the trap catches using effective radius. Bull. Entomol. Res. 65 (2):303-348. https://doi.org/10.1017/ S000748530000599X

Chin, H., Y. Othman and P.A.C., Ooi. 1990. The diamondback moth problem in Malaysia. In: Management of Plutella xylostella in Malaysia: Problem and Prospects. MARDI, Kuala, Lumpur. 26.

FAO. 2008. Food and Agriculture Organization of the United Nations: Economic and social De- partment: The statistical Division. Report index at www.fao.org/es/ess/top/commodity.htm.

Harcourt, D.G. 1986. Population dynamics of the diamondback moth in Southern Ontario. p. 3-5. In: "Management of Diamondback Moth and other Crucifer Pests: Proc. In-terntl. Workshop" (N.S. Talekar, ed.). Tainan, Taiwan, 11-15 March.

Hartcourt, D.G. 1957. Biology of diamondback moth Plutella maculippenis (Curt) In eastern Ontario11. Life History; behaviour and host relationship. Can. Entomol. 89: 554-64. https:// doi.org/10.4039/Ent89554-12

Hemchandra, O. and T.K. Singh. 2007. Population dynamics of DBM, Plutella xylostella (L.) on cabbage agro-ecosystem in Manipur. Indian J. Entomol. 69:154-61.

Kfir, R. 1998. Origin of the diamondback moth (Lepidoptera: Plutellidae). Ann. Entomol. Soc. Amer. 91: 164-167. https://doi.org/10.1093/ aesa/91.2.164

Leu F.M. and H.S. Lee. 1984. Observation of the life history of diamondback moth, P. xylostella (L.) in whole year. J. Agric. Res. China. 33: 424430.

Löhr, B.R. Kahuthia-Gathu, C. Kariuki, J. Obiero and G. Gichini. 2007. Impact of an exotic parasitoid on Plutella xylostella (Lepidoptera: Plutellidae) population dynamics, damage and indigenous natural enemies in Kenya. Bull. Entomol. Res. 97: 337-350. https://doi.org/10.1017/ S0007485307005068

Maelzer, D.A, M.P. Zalucki and R. Laughlin. 1996. An analysis of historic light trap data for $\mathrm{Hel}-$ icoverpa punctigera: Forecasting the size of pest population. Bull. Entomol. Res. 86: 547-557. https://doi.org/10.1017/S0007485300039341

Mohamed, F.R. Khan, P. Randall, G. Griffin, G.R. Carner and C.S. Gorsuch. 2004. Diamondback Moth (Lepidoptera: Plutellidae) Population Density and Parasitism by Diadegma insulare on Collard in South Carolina. J. Agric. Urban Entomol. 21(3):164-170.

Mushtaque, M., A.I. Mohyuddin, T. Zafar and M. Irshad. 1995. Notes on the important lepidopterous pests of crucifers and their natural enemies in Pakistan. Pak. Entomol. 17 (1-2): 109-116.

Muthuthantri, S., D.A. Maelzer, M.P. Zalucki, and A.R. Clarke. 2010. The seasonal phenology of Bactrocera tryoni (Froggatt) (Diptera: Tephriti- 
dae) in Queensland. Aust. J. Entomol. 49: 221233.

Nyambo, B.T. and A. Pekke. 1995. Brassica Pest Management. In Proceedings of the Brassica planning workshop for East and South Africa Region. Lilongwe, Malawi $15^{\text {th }}-18^{\text {th }}$ May.

Patra, S., V.W. Dhote, S.K. F. Alam, B.C. Das, M.L. Chatterjee and A. Samanta. 2013. Population dynamics of major insect pests and their natural enemies on cabbage under new alluvial zone of West Bengal. J. Plant Prot. Sci. 5(1): 42-49.

Shelton, A.M. 2001. Regional outbreaks of diamondback moth due to movement of contaminated plants and favourable climatic conditions. p. 96-101. In: Proc. IV Int. Workshop "Management of Diamondback Moth and other Crucifer Pests”. Melbourne, 26-29 Nov. 2001.

Shelton, A.M. 2004. The management of diamondback moth and other crucifer pests. Proceedings of the Fourth International Workshop, 26-29 November 2001. Melbourne. Melbourne, Australia: Department of Natural Resources and Environment. pp. 3-8.

Thorsteinson, A.J. 1953. The chemotactic responses that determined host specificity in an oligophagous insect (Plutella maculipennis (Curt.) (Lepidoptera). Can. J. Zool. 31 (1): 52-72. https:// doi.org/10.1139/z53-006

Venkateswarlu, V., R.K. Sharma, S. Chander and S.D Singh. 2011. Population dynamics of major insect pests and their natural enemies in cab- bage. Annal. P1 Prot. Sci. 19: 272-77.

Verkerk, R.H.J. and D.J. Wright. 1996. Multi tropic interactions and management of the diamondback moth: a review. Bull Entomol. Res. 86: 205-216. https://doi.org/10.1017/ S0007485300052482

Vickers, R.A, M.J. Furlong, A. White and J.K. Pell. 2004. Initiation of fungal epizootics in diamondback moth populations within a large field cage: Proof of concept of auto-dissemination. Entomol. Experimentalis et Applicata 111:7-17. https://doi.org/10.1111/j.00138703.2004.00140.x

Warwick, S.I., A. Francis and G.A. Mulligan. 2003. Brassicaceae of Canada. Government of Canada. Available: http://www.cbif.gc.ca/spp_pages/brass/index_e.php

You, M.S. and H. Wei. 2007. The research of diamondback moth. China Agriculture Press. China.

Zada, H., A.U.R. Saljoqi, A. Farid., F. Ullah and I.A. Khan. 2014. Influence of weather parameters on population dynamics of apple codling moth Cydia pomonella (Lepidoptera; Tortricidae) at Matta Swat valley. Sarhad J. Agric. 30(3): 351-356.

Zalucki, M.P., D. Adamson and M.J. Furlong. 2009. The future of IPM: Whither or wither? Aust. J. Entoml. 48: 85-96. https://doi.org/10.1111/ j.1440-6055.2009.00690.x 